\title{
Transtherapy for moderate to severe acne scar: a study of 2 cases
}

\author{
Soo-Hyun Sung ${ }^{1}$, Jong-Hyun Park ${ }^{2}$, Chang-Hyun Han ${ }^{3}$, Seung-Min Hong ${ }^{4}$, \\ Eun-Jung Park ${ }^{5}$, Ho-Ik Na ${ }^{6}$, Sung-Jin Park ${ }^{6}$, Ji-Hee $\mathrm{Yu}^{6}$, Ji-Hun $\mathrm{Ha}^{6}$ \\ ${ }^{1}$ Group for Support of the Policy, Korea Promotion Institute for Traditional Industry \\ ${ }^{2}$ Department of Pathology, College of Korean Medicine, Dae-Gu Haany University \\ ${ }^{3}$ Department of Clinical Research Division, Korea Institute of Oriental Medicine \\ ${ }^{4}$ Department of Sasang Constitutional Medicine, Gradeute School of Korean Medicine, Kyunghee University \\ ${ }^{5}$ Information System Unit, Samsung Securities \\ ${ }^{6}$ Empress Oriental Medical Clinic
}

\begin{abstract}
Objectives: The purpose of this study is to present effect of transtherapy which is treatment of Korean Medicine to acne scar patients.

Methods: We used transtherapy to moderate and severe acne scar patients and evaluated by a Photo evaluation with 10-point score and Qualitative Global Acne Scarring Grading System.

Results: After transtherapy treatment, mean of Qualitative Global Acne Scarring Grading System of patients changed from $3.5 \pm 0.71$ to $1.5 \pm 0.71$. Acne scar showed an improvement at least 8 up to 9 and mean of their acne scar improvement scores was $8.33 \pm 0.52$ on photo evaluation with 10 -point score.

Conclusions: This paper shows that transtherapy in the treatment of moderate to severe acne scars is beneficial for promoting skin regeneration.
\end{abstract}

$\overline{K e y}$ Words : Korean medicine, Transtherapy, Acne scar

\section{Introduction}

Acne is a disorder that appears in various forms, such as comedones, papules, pustules, nodules, and clot, mostly occurs in adolescence ${ }^{1-2)}$. About $80-90 \%$ of adults in Korea are known to be experienced or currently suffering from acne ${ }^{3)}$. The pathogenesis of acne is still remain unknown, but 4 factors are expected to play an important role: (1) trichilemmal keratinization, (2) increased sebum secretion, (2) bacterial growth, (3) inflammation ${ }^{4}$.

Acne scars can be divided into two major types:
(1) pigmentation of the skin, red marks of the skin (2) defects of the skin caused by necrosis of skin tissue. Symptoms like pigmentation or red marks may disappear over time, but defect type scars that caused by severe inflammation and defect to the underlying tissue or dermis remain intact over time ${ }^{5}$.

In the treatment of acne scars, laser resurfacing or chemical peels, invasive methods (punch elevation, subcision), and injection of tissue expanders (hyaluronic acid, collagen, fat, etc.) in depressed scar points shown to good effect, but moderate to severe scars of tissue defect types have shown the limits ${ }^{6-9}$.

\footnotetext{
- Received : 30 November 2015

- Revised : 21 December 2015

- Accepted : 21 December 2015

- Correspondence to : Ji-Hun Ha

570-2, Sinsa-dong, Gangnam-gu, Seoul, 06031, Korea

Tel : +82-2-543-9696, Fax : +82-2-543-9609, E-mail : gkwlgns@hanmail.net
} 
Recently, in complementary medicine, treatments such as herbal medicine ${ }^{10)}$, topical herbal compress ${ }^{11)}$, and micro-acupuncture ${ }^{12-14)}$ has been reported that represents a good effect in the treatment of acne itself. Still, treatment for acne scars and study about that is insufficient. In this study, we performed acupuncture treatment which is an application of Korean Medicine to patients with acne scars and report several case with good effects.

\section{Methods}

\section{Patients}

We presented our experience with 2 patients who met following three conditions between November, 2014 and October, 2015 in the Empress Oriental Medical Clinic.

(1) Patients with acne scars (2) moderate to severe acne scar (grade 3 or 4 of qualitative global acne scarring grading system) (3) no other underlying facial diseases. During treatment for this study, other drugs or therapies that may affect the acne scars were not permitted.

\section{Treatment process}

Before treatment, we wipe off the ointment of the treatment area with gauze, and then sterilize with povidone-iodine (Gumi povidone iodine soln, Gumi Pharm), cover the face with surgical drape with small hole and expose the treatment area. Then we performed transtherapy with $26 \mathrm{G}$ precision needle on the acne scars that are deep or wide. After transtherapy, we sterilize with povidone-iodine again, and press treatment area using $4 \times 4$ gauze for complete hemostasis, and wipe blood marks out with $4 \times 4$ gauze soaked in saline.

\section{Acupuncture: Transtherapy}

Acupuncture treatment used in this study named "transtherapy". This therapy combines perspective of
Korean Medicine theory and the conventional invasive methods that make wounds below the scar and induce regeneration. With inflow of healthy skin tissue from around scar tissue to scar site, this therapy stimulates the circulation of Qi and blood, helps ensure easier regeneration. Transtherapy was performed a total of two times at intervals of 1-3 months according to the patient's condition. The patients received the secondary treatment after his primary care to reduce swelling on face and skin redness.

Transtherapy was performed with a precision needle of 26G 1/2inch. (Disposable needle, BD) First, for incision between the epidermis and upper dermis of bottom of the scar, needle is shallowly inserted from $1-2 \mathrm{~mm}$ side of the scar. Next, we extended the incision $1 \mathrm{~mm}$ around the scar for micro-transplantation of the surrounding normal skin tissue.

Skin wrinkles can occur during insertion procedures. So in order to perform the treatment with correct depth, we have to hold the skin right next to the needle-inserted skin surface by assisting hand. The skin is to be maintained flat. When the needle passes tissues under the scar and reach the other normal skin tissue of the scar, the skin must be kept flat. In this process, the needle is put through the epidermis and dermis, that is, stratum basale or upper dermis. At the time of procedure, needle is passed through 0.1-0.2mm under the skin, enough to show through the skin. It should be a constant depth of needle procedures both the unit and the peripheral scar tissue. This procedure is to be $2-5$ times per scars, so become a fan-shape. Scars are flat and filled with bright red rash immediately after treatment.

\section{Assessment}

1) Photo evaluation with 10-point score

Before transtherapy, over 10 facial photographs per patients were taken, to reveal acne scars well. 
3-6 months after the procedure, photographs taken in the same condition were used to evaluate the final changes of patients. To assess the improvement of acne scar, three clinicians evaluate photos to 10-point scale (0-no change, 10-no scar) independently, and we used median value of three evaluations for final change score.

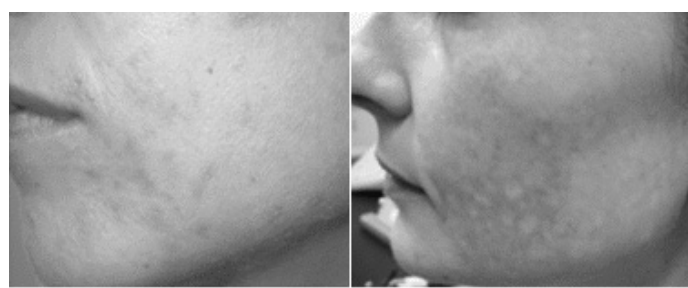

Grade 1 Macular disease

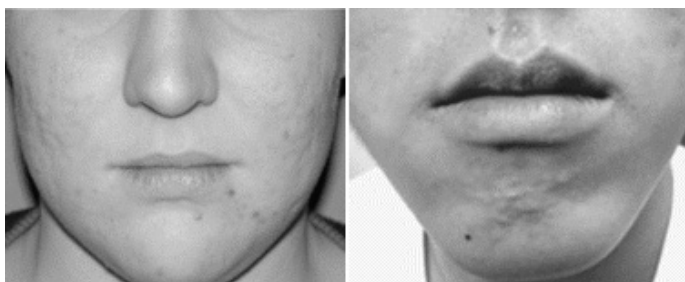

Grade 3 Moderate disease
2) Qualitative Global Acne Scarring Grading System

We classified the severity of symptoms of acne in patients based on the Global Acne Scarring Grading System in order to obtain objective assessments of acne severity before and after treatment (Fig. 1) $(\text { Table } 1)^{15)}$.

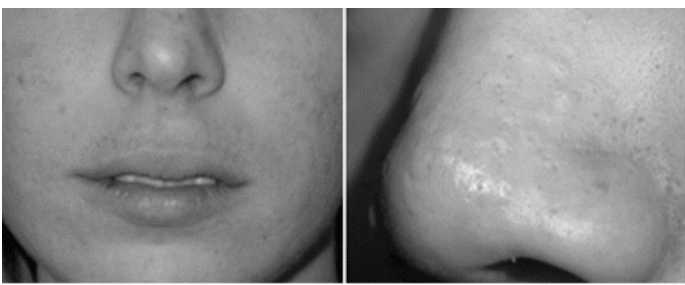

Grade 2 Mild disease

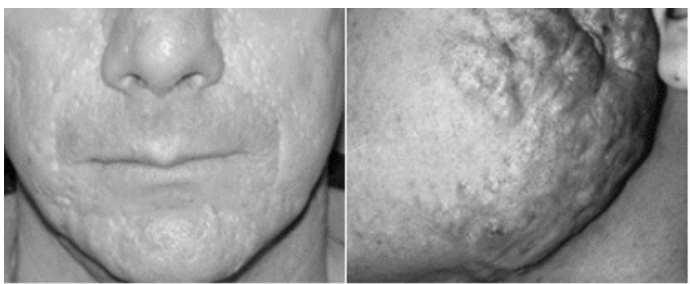

Grade 4 Sever disease

Fig. 1. Qualitative Global Acne Scarring Grading System Grade

Table 1. Grades and Examples of Postacne Scarring

\begin{tabular}{|c|c|c|c|}
\hline Grade & Level of disease & Characteristics & Examples of scars \\
\hline 1 & Macular disease & $\begin{array}{l}\text { Erythematous, hyper- or hypopigmented flat marks visible to } \\
\text { patient or observer irrespective of distance. }\end{array}$ & $\begin{array}{l}\text { Erythematous, hyper- or } \\
\text { hypopigmented flat marks }\end{array}$ \\
\hline 2 & Mild disease & $\begin{array}{l}\text { Mild atrophy or hypertrophy that may not be obvious at social } \\
\text { distances of } 50 \mathrm{~cm} \text { or greater and may be covered adequately } \\
\text { by makeup or the normal shadow of shaved beard hair in males } \\
\text { or normal body hair if extrafacial. }\end{array}$ & $\begin{array}{l}\text { Mild rolling, small soft } \\
\text { papular }\end{array}$ \\
\hline 3 & Moderate disease & $\begin{array}{l}\text { Moderate atrophic or hypertrophic scarring that is obvious at } \\
\text { social distances of } 50 \mathrm{~cm} \text { or greater and is not covered easily by } \\
\text { makeup or the normal shadow of shaved beard hair in males or } \\
\text { body hair if extrafacial, but is still able to be flattened by } \\
\text { manual stretching of the skin. }\end{array}$ & $\begin{array}{l}\text { More significant rolling, } \\
\text { shallow "boxcar," mild to } \\
\text { moderate hypertrophic or } \\
\text { papular scars }\end{array}$ \\
\hline 4 & Sever disease & $\begin{array}{l}\text { Severe atrophic or hypertrophic scarring that is obvious at } \\
\text { social distances of } 50 \mathrm{~cm} \text { or greater and is not covered easily by } \\
\text { makeup or the normal shadow of shaved beard hair in males or } \\
\text { body hair (if extrafacial) and is not able to be flattened by } \\
\text { manual stretching of the skin. }\end{array}$ & $\begin{array}{l}\text { Punched out atrophic (deep } \\
\text { "boxcar"), "ice pick", bridges } \\
\text { and tunnels, gross atrophy, } \\
\text { dystrophic scars significant } \\
\text { hypertrophy or keloid }\end{array}$ \\
\hline
\end{tabular}




\section{Case Report}

\section{〈case 1〉}

A 28-year-old male patient with no relevant treatment experience. Acne occurs in high school age. Transtherapy was performed a total of two times at intervals of 1 month. Final evaluation was performed at 2.5 month after the last transtherapy. Before the treatment, bumps and dents appears prominently across the forehead and cheeks widely. After the treatment, most dents became flat, the status of remaining of some bumps and pigmentations was observed (Fig. 2).

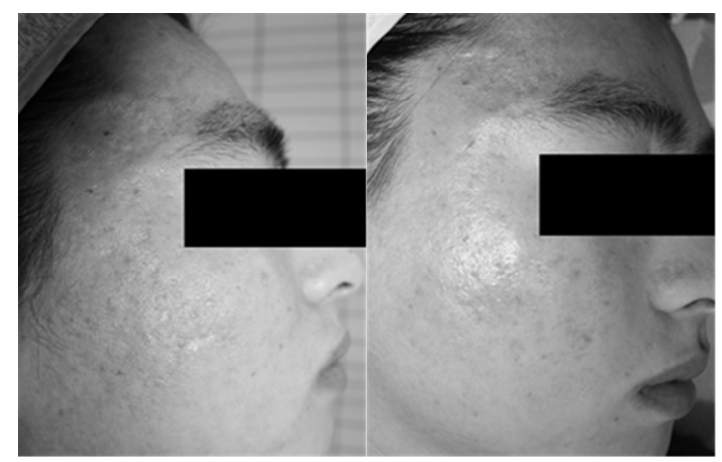

Fig. 2. Before treatment and after treatment of patient(case1)

\section{〈case 2〉}

A 32-year-old male patient who has experience fractional photothermolysis, subcision, and dot peeling in dermatology clinic. Acne occurs in middle-high school age. Transtherapy was performed a total of two times at intervals of 1 month. Final evaluation was performed at 3 month after the last transtherapy. a number of boxcar type acne scars seen around the cheeks was lost after the treatment. According to the qualitative global acne scarring grading system, grade 3(moderate) scars became grade 1(macular), erythematous, hyper-pigmented flat marks (Fig. 3).

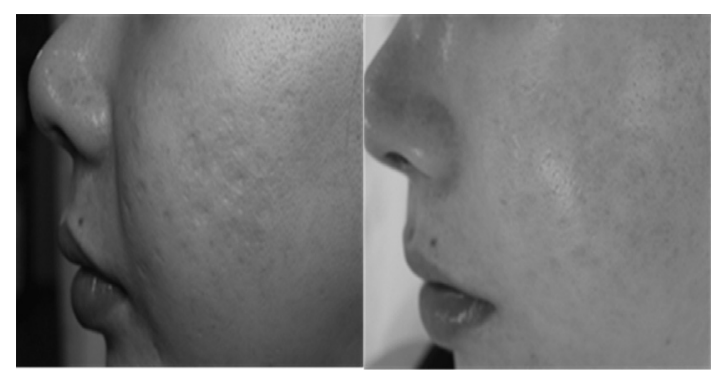

Fig. 3. Before treatment and after treatment of patient(case2)

\section{Results}

2 patients were male and their average age were thirty years old. According to their medical history, 1 patient has never had acne treatment and another patient had fractional photohtermolysis, subcision, and dot peeling (Table 2).

Table 2. General Information of Patients

\begin{tabular}{lc}
\hline Sex (Male/Female) & $2 / 0$ \\
\hline Age (Mean) & 30 \\
\hline Number of treatment(trans therapy) & 2 \\
\hline Treatment experience (multiple responses) & \\
none (n) & 1 \\
fractional photothermolysis (n) & 1 \\
dot peeling (n) & 1 \\
subcision (n) & 1 \\
\hline
\end{tabular}

In clinical evaluation before and after treatment by three clinicians, Qualitative Global Acne Scarring Grading System of patients changed from 3.5 \pm 0.71 to $1.5 \pm 0.71$. Scores of acne scar improved at least 8 up to 9 scores on photo evaluation with 10-point score and average of their acne scar improvement scores was $8.33 \pm 0.52$ on photo evaluation (Table 3 ).

\section{Discussion}

Acne is a relatively common skin disorder. 4 factors - (1) abnormal trichilemmal keratinization (2) increased sebum secretion (3) bacterial growth such as propionibacterium acnes (4) inflammation - are 
Table 3. Scores and Grading of Patients before and after Transtherapy

\begin{tabular}{ccccccc}
\hline \multirow{2}{*}{$\begin{array}{c}\text { patients } \\
\text { number(sex/age) }\end{array}$} & \multicolumn{2}{c}{$\begin{array}{c}\text { qualitative global } \\
\text { acne scarring grade }\end{array}$} & \multicolumn{4}{c}{ photo evaluation with 10-point score } \\
\cline { 2 - 8 } & before & after & clinician A & clinician B & clinician C & Mean score \\
\hline Case1(M,28) & 4 & 2 & 8 & 8 & 8 & 8 \\
\hline Case2(M,32) & 3 & 1 & 8 & 9 & 9 & $8.67 \pm 0.58$ \\
\hline Mean & $3.5 \pm 0.71$ & $1.5 \pm 0.71$ & 8 & $8.5 \pm 0.71$ & $8.5 \pm 0.71$ & $8.33 \pm 0.52$ \\
\hline
\end{tabular}

expected to play an important role to cause acne. Some of patients with severe inflammatory responses and tissue damage and defect may have permanent scarring, and are often stressful in social life ${ }^{5)}$.

Scars of tissue defect type that appear depressed shape on the surface of the skin are classified according to the appearance of scars: rolling type, boxcar type, icepick type. These scars are known to be difficult to recover compared to the pigmentation type scars ${ }^{16)}$.

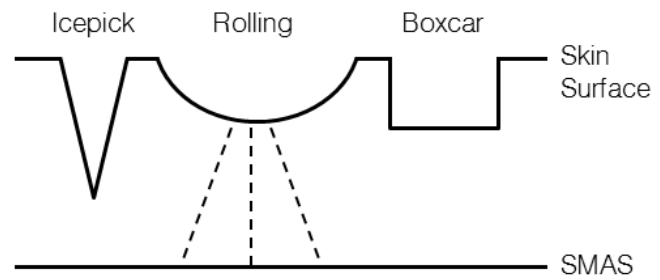

Fig. 4. Acne Scar Subtypes

The way to treat scars like this defect type is dermabrasion to cut out around the scar tissue or surgical methods such as punch graft, punch elevation, and punch excision. The most frequently used method recently is to scratch the bottom of the scar to occur skin regeneration. There are two ways to scratch the scar: (1) Using sharp metal objects like roller-needle and multiple lancing needle, (2) Using a laser system. (Fraxel laser, ablative fractional $\mathrm{CO} 2$ laser) These ways do not need general anesthesia or surgical procedure, procedure is relatively easy and has good effects, so widely used in clinics. This procedure can have good effect if the skin damage is less severe. However, in severe skin damage, less than $20 \%$ of normal skin tissue remains below the scar, regeneration is not occur effectively ${ }^{17)}$. In that case, surgical transplant method (punch graft, punch elevation, autologous micro fat graft, and autologous dermal graft) may be used, but there is a risk of side effects compared to treatment effects, so it does not widely used.

Therefore, not only using a method that simply bruised scar to regeneration, micro-transplantation of normal skin tissue of adjacent areas of the scar using needles can increase the effect of therapy. In view of Traditional Korean Medicine, longitudinal flow as well as transversal action (flow of Qi and blood) is also considered important to life support, regeneration and recovery. In this therapy, normal skin cells may move from not the bottom wall (longitudinal direction) but the lateral wall (transversal direction) of the scar. Because the cell is moved in transversal direction, so we named this procedure "trans-therapy". (The meaning of micro-transplantation and movement) "Trans" is meant to be "transcendence, transformation, passing through", so by passing through skin cells between normal skin tissue and the scar tissue, this therapy helps the movement of the normal skin cells. The process of scratching the bottom of scar is also different from conventional subsicion therapy. Subsicion therapy is aimed at cutting the fibrous bands that connected from lower dermis to SMAS under the scar ${ }^{14)}$. In contrast, transtherapy is not aimed at lower dermis, but aimed at stratum basale 
and upper dermis that directly affect the regeneration of epidermis. These cells that adjacent to the scar transplanted to under the scar with blood to further probably improve the regeneration effect.

In this study, 2 patients with moderate to severe acne scares received transtherapy twice. Acne scar changing before and after treatment were observed. 2 patients were observed in the change of acne scars before and after treatment photos. Since aimed at improving the depressed scar, in some cases, pigmentations was still remaining.

In clinical evaluation before and after treatment by three clinicians, Qualitative Global Acne Scarring Grading System of patients changed from $3.5 \pm 0.71$ to $1.5 \pm 0.71$. Acne scar showed an improvement at least 8 up to 9 scores on photo evaluation with 10-point score. (average $8.33 \pm 0.52$ ) Overall, sinking deep scars were getting lost or shallower after treatment, skin regeneration occurred, it seems to be a good therapeutic effect shown.

The advantage of this therapy is less side effects compared to laser therapy and surgical therapy. And this is a general process of skin regeneration rather than an artificial improvement, it can lead to change in a more natural way. More even, relatively deep acne scar treatment is possible, so it can be used widely in clinic. In this study, there were no side effects reported cases, but additional studies are needed for observation of common side effects such as inflammation after therapy. Further studies about adjunctive therapy for enhancing the effect of treatment (including pharmacopuncture) using more cases needed.

\section{Conclusion}

In conclusion, transtherapy may be effective in the treatment of moderate to severe acne scars, and could be applied in clinical practice.

\section{Conflicts of interest}

The authors declare that there is no conflict of interest regarding the publication of this paper.

\section{References}

1. Ahn SK. Acne Bible. Seoul:Jinsol. 2006:61.

2. Hong SH. The clinical study on the effect of Jeondo-san(Diandao-san) on acnes. J Korean Oriental Med. 2005;26(3):74-79.

3. Jung JY. Medical skin care. Seoul:MDworld. 2010:1066, 1138.

4. Thiboutot DM, Strauss JS. Diseases of the sebaceous glands. In:Freedberg IM, Eisen AZ, Wolff K, Austen KF, Goldsmith LA, Katz SI, editors. Textbook of dermatology. 6th ed. New York:McGraw-Hill. 2003:672-63.

5. Tosti A, Padova MD, Beer K. Acne Scar -Classification and treatment. Seoul:Gabon Medical Book, Inc. 2010:1-61.

6. Huang L. A new modality for fractional $\mathrm{CO} 2$ laser resurfacing for acne scars in Asians. Lasers Med Sci. 2012.

7. Khunger N. Standard guidelines of care for acne surgery. Indian J Dermatol Venereol Leprol. 2008;74:28-36.

8. Ramadan SA, El-Komy MH, Bassiouny DA, El-Tobshy SA. Subcision versus $100 \%$ trichloroacetic acid in the treatment of rolling acne scars. Dermatol Surg. 2011;37(5):626-33.

9. Lee JW, Kim BJ, Kim MN, Lee CK. Treatment of acne scars using subdermal minimal surgery technology. Dermatol Surg. 2010;36(8):1281-7.

10. Oh CS, Kim MS, Kim I, Kim HY, Park SI, Choi SI, et al. Acne treatment cases with Hwangryeonhaedok-tang. The Journal of Korean Oriental Medical Ophthalmology \& Otolaryngology \& Dermatology. 2009;22(3):228-36.

11. Kim JS, Kim GJ. The clinical observation of 8 cases of acnes diseases. The Journal of Oriental 
Medical Surgery, Ophthalmology \& Otolaryngology. 2001;14(1):66-75.

12. Seong EJ, Jo EH, Park MC. A clinical report on the acne treatment with AMTS. The Journal of Korean Oriental Medical Ophthalmology \& Otolaryngology \& Dermatology. 2010;23(3): 236-46.

13. Youh EJ, Choi YS, Kim JI, Ko HK. The study on the acupuncture therapy of acne. The Journal of Korean Acupuncture \& Moxibustion Medicine Society. 2006;23(4):123-34.

14. Lee KS, Kim YR, Choi HS. Case study of treating acne scar using scar regeneration acupuncture therapy and micro-needle therapy.
The Journal of Korean Acupuncture \& Moxibustion Medicine Society. 2012;29(4):81-91.

15. Goodman GJ, Baron JA. Postacne scarring: a qualitative global scarring grading system. Dermatol Surg. 2006;32(12):1458-66.

16. Jacob CI, Dover JS, Kaminer MS. Acne scarring: a classification system and review of treatment options. J Am Acad Dermatol. 2001;45(1): 109-17.

17. Fabbrocini G, Fardella N, Monfrecola A, Proietti I, Innocenzi D. Acne scarring treatment using skin needling. Clin Exp Dermatol. 2009; 34(8):874-9. 